\title{
As representações sociais de mulheres portadoras de Hipertensão Arterial
}

\author{
Social representations of women who live with High Blood Pressure
}

Las representaciones sociales de mujeres que tienen Hipertension Arterial

\author{
Maria Enoia Dantas Costa e Silva', Liana Dantas da Costa e Silva Barbosa', \\ Adélia Dalva da Silva Oliveira' , Márcia Teles de Oliveira Gouveia", \\ Benevina Maria Vilar Teixeira Nunes', Eucário Leite Monteiro Alves ${ }^{1}$ \\ 'Faculdade NOVAFAPI. Teresina, PI \\ "Universidade Federal do Plauí, Teresina, PI
}

Submissão: 13/02/2007

Aprovação: 01/12/2007

\begin{abstract}
RESUMO
A Hipertensão Arterial, grave problema de Saúde Pública, afeta grande parte da população mundial e apresenta dificuldades para seu controle. Este estudo teve como objetivo apreender as representações sociais de mulheres, sobre o "ser portadora da doença", no contexto familiar, explorando aspectos psicossociais relacionados a sentimentos e comportamentos capazes de influenciar práticas de tratamento e controle da doença. Realizado em Teresina-PI, com 25 mulheres assistidas num centro de saúde. As informações coletadas foram organizadas num "corpus" processado pelo software ALCESTE 4.5. Emergiram três unidades de contexto inicial (u.c.i.), apontando as manifestações / sentimentos / representações sociais das portadoras. Estas influenciam na produção e circulação de conhecimentos Que orientam e definem comportamentos e condutas destas mulheres.
\end{abstract}

Descritores: Hipertensão Arterial; Assistência de Enfermagem; PesQuisa Qualitaitva.

\begin{abstract}
The Arterial Hypertension is considered as a serious Public Health problem that affects most of the world population and presents difficulties to control. This study dealt with the social representations of the women carriers of Arterial Hypertension about what it is like to be carriers of the disease in the family context, and the health services provided by the professionals that care for them and exploring the psychosocial aspects related to their feelings and behavior that might interfere in their treatment and control of the disease. It was performed in Teresina - PI with 25 women assisted in the Health Center. The data collected was organized in a "corpus" and submitted to the ALCESTE software 4.5, which produced three initial context units, showing the manifestations and feelings of the carriers. The social representations influence the process of knowledge production and circulation that guide and define the behavior and conducts of the hypertensive disease carrier.
\end{abstract}

Descriptors: Arterial Hypertension; Nursing care; Qualitative research.

\section{RESUMEN}

La hipertensión arterial, problema de salud pública serio Que afecte la mayor parte de a población del mundo, requiere la búsqueda para dificultades. El actual estudio se ocupó apreender de las representaciones sociales de los portadores de las mujeres sobre como cuál es ser portadores del la enfermedad en el contexto de la familia, y explorando los aspectos sicosociales se relacionó con sus sensaciones y comportamiento que pudieron interferir en su tratamiento y control de la enfermedad. Realizado en Teresina con 25 mujeres registradas en un centro de la salud. La información fue organizada en una "recopilación" y sometida al software 4.5 de ALCESTE, procesó la "recopilación" integrada por 3 unidades iniciales del contexto, demostrar las manifestaciones explicativas de los portadores sobre el tratamiento y el control de la enfermedad. Las representaciones sociales influencian el proceso de la producción y de la circulación del conocimiento Que dirigen y definen el comportamiento y las conductas del portador hipertenso de la enfermedad.

Descriptores: Hipertensión Arterial; Atención de enfermería; Investigación cualitativa.

Correspondência: Maria Enoia Dantas Costa e Silva. Rua Vitorino Orthige Fernandes, 6I23. Bairro do Uruguai - CEP: 64057- I00. Teresina, PI. 


\section{INTRODUÇÃO}

As doenças cardiovasculares constituem a principal causa de morbi-mortalidade na população brasileira, sendo Que a Hipertensão Arterial (HA) representa um dos principais fatores de risco para o agravamento desse cenário, por estar relacionada ao surgimento de outras doenças crônicas não transmissíveis, Que trazem repercussões negativas para a Qualidade de vida.

Quando não tratada adeQuadamente, a HA pode acarretar graves conseQüências a alguns órgãos vitais como cérebro, coração e rins, constituindo, desse modo, um dos mais graves problemas de saúde pública, merecendo, portanto, ser estudado por aqueles Que se encontram envolvidos direta ou indiretamente com esta problemática.

Abordar a Hipertensão Arterial como sério problema de Saúde Pública Que afeta grande parte da população mundial implica em se procurar conhecer as diversas dificuldades de caráter psicossocial, econômico, biológico e cultural Que envolve seus portadores. Nesse sentido, entender tais dificuldades torna-se relevante, principalmente ao articulá-las às condições de produção de conhecimento sobre a doença, no imaginário social. Este conhecimento possibilita a identificação de sentimentos e experiências vivenciadas pelos portadores, em suas relações sócio-familiares e com profissionais de saúde Que os assistem.

A Hipertensão Arterial, mesmo Que reconhecida como problema relevante, ainda apresenta seu tratamento e controle inadequados, embora os avanços científicos e tecnológicos nas últimas décadas venham facilitando a identificação dos fatores de risco, do diagnóstico precoce de seus agravos, o emprego de nova terapêutica medicamentosa e as ações educativas para as mudanças no estilo de vida, promovidas por diferentes meios de comunicação, destacandose a atuação dos profissionais de saúde, em especial, os da rede básica, em todos os municípios brasileiros.

Contudo, apenas parte dos portadores Que mantém valores satisfatórios da pressão arterial (PA<140 / 90 Mmhg) usa a medicação de forma correta e adere às medidas terapêuticas, especialmente, as Que envolvem mudanças de hábitos alimentares, abandono de vícios como o tabagismo, alcoolismo e a incorporação de atividades físicas. Com isso, a prevenção e tratamento da doença passam a representar desafios às autoridades sanitárias, profissionais de saúde, portadores e familiares envolvidos na promoção de saúde ${ }^{(1)}$.

Na concepção de muitos estudiosos, as dificuldades de controle da HA estão relacionadas às características da doença, como o caráter assintomático, a evolução lenta, a cronicidade, Que fazem com Que não seja considerada doença ou algo Que precise ser cuidado. Assim, os portadores não sentem necessidade de modificar os hábitos relacionados ao trabalho, ao meio social e à dinâmica familiar, até Que surjam as primeiras complicações provocadas pela $\operatorname{doença(~}^{(2)}$.

A adesão de portadores ao tratamento da doença está submetida a influências, podendo estar relacionada à própria enfermidade, com suas características de cronicidade e sintomatologia inespecífica, e ao tratamento Que envolve mudanças no estilo de vida, além do uso constante de medicamentos. Outros fatores condizentes com a adesão são as Questões institucionais associadas à dispensação de medicamentos e, ainda, a dificuldade de acesso às ações de controle. Por outro lado, os portadores apresentam aspectos biológicos, hereditários, sócio-econômicos e psicossociais, Que favorecem a doença ${ }^{(3)}$.

Quanto aos aspectos psicossociais, estes, em geral, estão relacionados às crenças sobre a doença, à modificação dos hábitos e costumes necessários à convivência de seus portadores no âmbito sócio-familiar. Esta convivência reQuer não apenas as mudanças na forma de viver, mas no entendimento relativo ao processo saúde/ doença. Considera-se que cada indivíduo, com base em experiências pessoais, manifesta concepções sobre este processo, as Quais apresentam estreita relação com suas crenças, pensamentos e sentimentos.

Nesse sentido, procurar entender os portadores de HA, com base numa concepção subjetivista, com prioridade na integração desses portadores com seus familiares, significa ampliar as possibilidades de controle da doença e as medidas de prevenção, para evitar o aumento do número de casos, de mortes ou seeüelas Que crescem indiscriminadamente em todo o mundo ${ }^{(4)}$.

$\mathrm{Na}$ busca dessa dimensão, este estudo objetivou as Representações Sociais de mulheres portadoras de Hipertensão Arterial sobre o que é "ser portadora da doença", no contexto familiar; e explorar os aspectos psicossociais relacionados aos sentimentos e comportamentos, capazes de influenciar nas práticas de tratamento e controle da doença.

A motivação pelo tema do estudo surgiu da experiência profissional das autoras, em assistir portadores de Hipertensão Arterial, na rede básica de saúde do município de Teresina, onde realizam ações educativas, consultas, reuniões e visitas domiciliares voltadas ao controle da doença. Essa experiência possibilitou a observação de Que as portadoras não se percebem doentes de HA, mas, em geral, encaramna como mal-estar passageiro, embora sejam conscientes dos riscos de morte e das seeüelas incapacitantes e suas complicações.

Nesse contexto, é elevado o número de portadores que ainda não responde satisfatoriamente às recomendações para o tratamento e controle da doença, ainda Que priorizadas as ações educativas propostas pelo Programa Nacional de Educação e Controle da Hipertensão Arterial do Ministério da Saúde. Essas ações envolvem orientações para o autocuidado, para o tratamento medicamentoso e mudanças no estilo de vida pertinentes ao controle dos fatores de risco Que predispõem a doença e seus agravos ${ }^{(5)}$.

As orientações sobre a doença são enfocadas pelos profissionais de saúde Quase sempre voltadas aos aspectos biológicos, epidemiológicos, econômicos, sendo pouco priorizados os de caráter sócio-psicológicos e culturais. Além disso, outro fato a ser analisado diz respeito às ações educativas, as Quais são desenvolvidas de forma autoritária e distanciadas da realidade social, deixando-se de lado as crenças, os sentimentos, a cultura, os hábitos alimentares dos portadores com relação à Hipertensão Arterial.

$\mathrm{O}$ tratamento e controle da HA representam, nessa perspectiva, desafios às autoridades governamentais e profissionais de saúde Que assistem aos portadores. Na dimensão da subjetividade, a investigação das dificuldades de controle da doença possibilita a apreensão de pensamentos, sentimentos e percepções face às vivências presentes nas crenças, atitudes, valores e informações, segundo as experiências do processo comunicacional entre estes.

Com base no exposto, supõe-se Que a articulação entre Hipertensão Arterial e as Representações Sociais sobre o que é "ser portador" de HA poderá contribuir para o entendimento da 
construção psicossocial da doença no âmbito da adoção de medidas preventivas por profissionais de saúde e na compreensão de comportamentos dos portadores frente à doença.

\section{A Hipertensão Arterial e as Representações Sociais}

A partir do conhecimento da problemática da HA e das ações propostas para a assistência aos portadores, observa-se Que os sujeitos deste estudo, mulheres portadoras, estão inseridos em uma realidade social Que passa por constantes transformações. Diante dessas mudanças, necessita-se entendê-las para se posicionarem e com isso definirem essa realidade, orientando-se através das formas de pensamentos, de ação e de comunicação, em seus grupos de pertença.

A relação Que se estabelece entre a HA e estes sujeitos encontrase permeada de conhecimentos advindos de seus diferentes contextos sócio-históricos, Que se organizam em verdadeiros emaranhados de significados, permitindo a apreensão dos acontecimentos da vida diária, das características do meio ambiente e das informações que aí circulam sobre este objeto.

Não existe uma realidade objetiva a priori, mas uma realidade em Que ocorrem constantes transformações e Que, por isso, é reapropriada e reconstituída pelo sistema cognitivo dos sujeitos Que integram um novo objeto em seus sistemas de valores, dependendo de sua história, de seus contextos social e ideológico ${ }^{(6)}$.

Dessa forma, este estudo considera Que as mulheres portadoras de HA têm conhecimentos espontâneos sobre a doença, ou seja, um saber de senso comum através do Qual se comunicam socialmente e se orientam.

Em face ao exposto, há a necessidade de se perceber o papel desta modalidade de conhecimento, buscando entender a inserção desses sujeitos em seus grupos de "pertença”, bem como compreender como suas representações orientam comportamentos frente ao processo pró-saúde. Além disso, cabe ressaltar a importância do reconhecimento Que essas representações sociais assumem na comunicação dessas portadoras e dos profissionais Que lidam com elas ${ }^{(7)}$.

As Representações Sociais são provenientes do julgamento do saber comum, elaborado a partir dos fenômenos Que emergem dos processos comunicacionais, os Quais repercutem sobre as interações e as mudanças sociais, respondendo as expectativas de interpretação do fenômeno observado ${ }^{(8)}$. No caso deste estudo, em torno da HA, de seu tratamento e controle.

A Teoria das Representações Sociais, a partir dos anos sessenta, vem sendo aplicada em estudos de diferentes áreas de conhecimento, considerando Que, associada a metodologias Que Ihe são apropriadas, fornece o campo representacional de grupos sociais sobre diferentes objetos de estudo.

Os diversos estudos no campo da enfermagem Que envolve essa teoria podem indicar a importância do estudo das Representações Sociais para a compreensão de Questões relacionadas à saúde, em Que a sua relevância pode possibilitar a apreensão de processos e mecanismos Que dão sentido aos objetos construídos pelos sujeitos concretos em suas relações cotidianas ${ }^{(9)}$.

A Representação Social da Psicanálise conceitua Representação Social como sendo "um sistema de valores, de noções e de práticas tendo uma dupla tendência: antes de tudo, instaurar uma ordem Que permite aos indivíduos a possibilidade de se orientar no meio- ambiente social, material e de dominá-lo"(10).

Esse sistema de valores apresenta a condição de "assegurar a comunicação entre os membros de uma comunidade, propondolhes um código para suas trocas e um código para nomear e classificar de maneira unívoca as partes de seu mundo, de sua história individual ou coletiva"(10).

Na realidade dos serviços, a HA e a adesão de mulheres portadoras às medidas de controle são representadas de formas distintas, uma vez Que os sujeitos legitimam socialmente diferentes apreensões, tanto relativas à doença em si como a essas medidas. As concepções determinam suas práticas em saúde, justificando e orientando suas atitudes, comportamentos e expectativas, frente às condições de vida, às crenças e à cultura desses diferentes sujeitos ${ }^{(7)}$.

Nessa perspectiva, a Teoria das Representações Sociais atende às expectativas de investigação e apreensão do conhecimento, posicionamentos, atitudes, sentimentos e comportamentos particulares desses sujeitos, bem como explora os aspectos subjetivos Que possam influenciar no controle da doença, a partir do saber informal estruturado socialmente e manifestado em suas condutas e comportamentos.

As experiências e vivências das pessoas com a doença encontramse inscritas num contexto ativo, dinâmico, Que participam da vida em coletividade, como prolongamento de seus comportamentos, tornando-os responsáveis pelo controle ou não da HA e, conseQüentemente, pela Qualidade de vida.

\section{METODOLOGIA}

Trata-se de uma pesquisa com método Qualitativo a Qual buscou identificar as Representações Sociais do "ser portador de Hipertensão Arterial”, elaboradas por mulheres portadoras no convívio familiar. Esta abordagem permite a compreensão de processos subjetivos, sejam estes grupais e/ou sociais.

A pesquisa foi realizada em Teresina-PI, com 25 mulheres cadastradas no Programa de Controle de Hipertensão Arterial, em um Centro de Saúde da Fundação Municipal de Saúde, as Quais foram selecionadas com base critérios estabelecidos segundo a Resolução 196/96 (11) do Ministério da Saúde e em função da disponibilidade em participar do estudo.

Por serem facilitadoras de expressão de características culturais e psicossociais e possibilitarem a obtenção de dados através de discussões cuidadosamente planejadas, as informações foram coletadas por meio de Quatro grupos focais, as Quais partiram da Questão: "o Que é ser portador de Hipertensão Arterial". Focalizando tal Questão, as participantes, sujeitos do estudo, expressaram crenças, percepções, valores, expectativas, anseios, receios e atitudes dos universos cultural e vocabular, Que compõem suas Representações Sociais, a respeito do assunto, num ambiente informal e descontraído ${ }^{(12)}$.

As informações, gravadas previamente, foram organizadas num "corpus" e submetidas ao software ALCESTE 4.5, programa que auxilia na análise de dados textuais, com base nas leis de distribuição do vocabulário de falas e textos ${ }^{(13,14)}$.

\section{RESULTADOS E DISCUSSÃO}

Numa seaüência lógica de operações, o software processou o 
"corpus" composto por sete unidades de contexto inicial (UCI), representando Quatro grupos focais e equivalendo às Representações Sociais do "ser portador da HA", Que se subdividiu em subeixos. Neste estudo, destacam-se o subeixo I, no Qual as classes 1 e 2 apontam as manifestações explicativas das portadoras sobre o tratamento e controle da doença, diretamente relacionadas à sua convivência no âmbito familiar; e o subeixo 2, com uma única classe (Classe 3), evidenciando os sentimentos dessas mulheres por serem portadoras de HA. Está parcialmente relacionada às duas classes anteriores (Figura 1 ).

Subeixo I - Controle da Hipertensão Arterial no convívio familiar, formado pelas Classes 1 e 2, aborda as manifestações explicativas do controle da doença, ressaltando os elementos sócio-cognitivos e os aspectos sócio-culturais e psicológicos das portadoras Que determinam seus posicionamentos e atitudes no enfrentamento da HA.

A Classe 1 - Tratamento e Controle da Hipertensão Arterial está diretamente relacionada à 2 e indiretamente à classe 3 , sendo constituída por 56 unidades de contexto elementar (UCE), Que evidenciam o conhecimento das portadoras sobre as formas de tratamento e controle da doença, em especial o tratamento medicamentoso, ressaltando os efeitos psicossociais negativos e positivos oriundos dessa terapêutica. Assim, as palavras em suas formas reduzidas, (Figura 1), objetivam as Representações Sociais das portadoras sobre o tratamento e controle da doença.

O conteúdo das unidades, (Figura 2) não só comprovam a presença das RS, mas de outros elementos Que permitem inferir Que as Representações Sociais das portadoras sobre o tratamento medicamentoso da doença são permeadas de sentimentos, por vezes, ambivalentes e contraditórios e Que revelam uma convivência desarmoniosa, marcada por freqüentes tensões articuladas e/ou associadas às preocupações do dia-a-dia, refletindo em insatisfação e insucesso para esta e outras formas de tratamento como um todo.

Essas unidades revelam também as crenças geradoras de preocupações relacionadas à observação rigorosa dos horários da medicação. Para as portadoras, ao não serem cumpridos ou alterados os horários, por esquecimento e/ou excesso de tarefas, a medicação não pode mais ser "tomada", pois, elas acreditam Que o "remédio" tomado fora de determinados "horários" traz malefício à saúde ao invés de controlar a pressão arterial:

(...) porque estou tomando meus remédios, estou bem controlada. (...) só tomo de noite. Na hora que eu sei que "vou" sair e não é no "horário" de "tomar" o "remédio", eu "levo" para "tomar" (...). Às vezes, é por causa da preocupação que eu não tomo na hora, me "esqueço". (...) Às vezes Quero me levantar e tomar logo, aí faço uma coisa, outra, vou escovar os dentes, fazer isso, fazer aquilo e tudo, depois tomar o café, aí, nesse incontinente me esqueço de tomar o remédio, no momento, mas não é todo dia, é lá uma vez. (...) aí, eu passo o dia todinho fazendo as coisas, vou buscar menino na escola.

Evidencia-se também Que as mulheres hipertensas reforçam

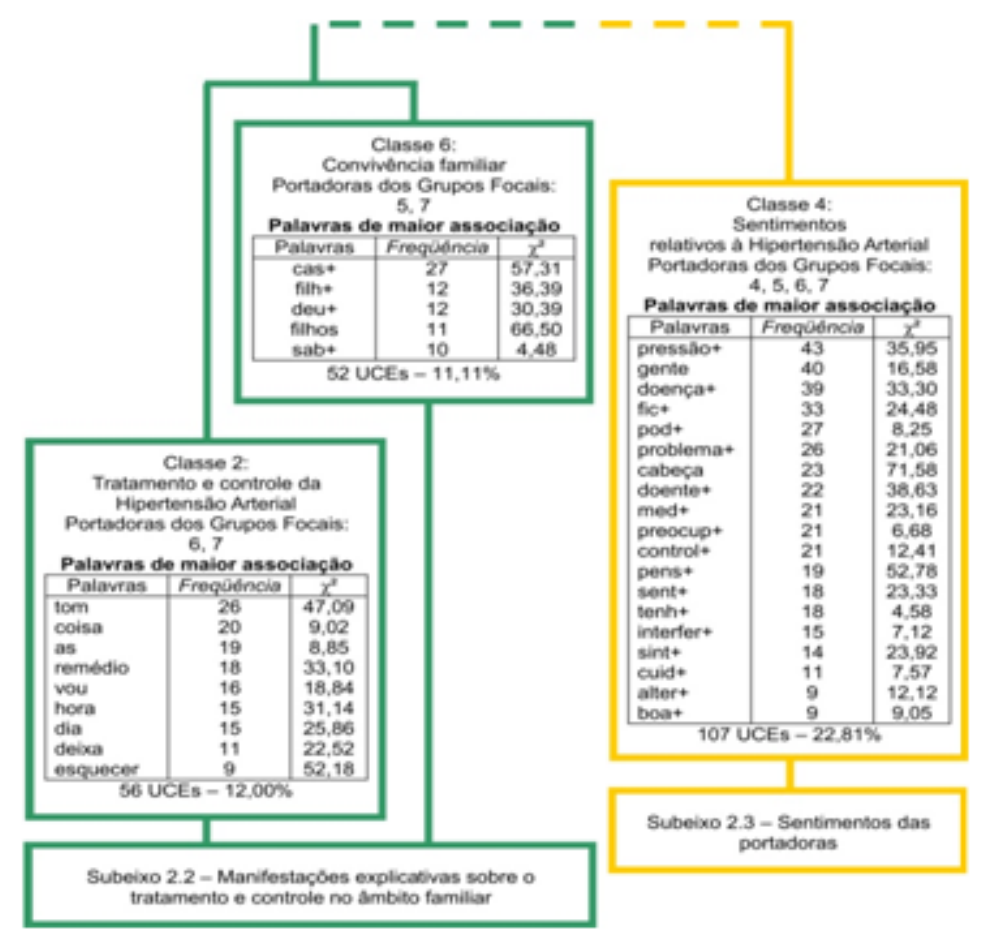

Figura 1. Dendograma das Classes de Representaçōes Sociais sobre o Ser Portador de Hipertensáo Arterial. 


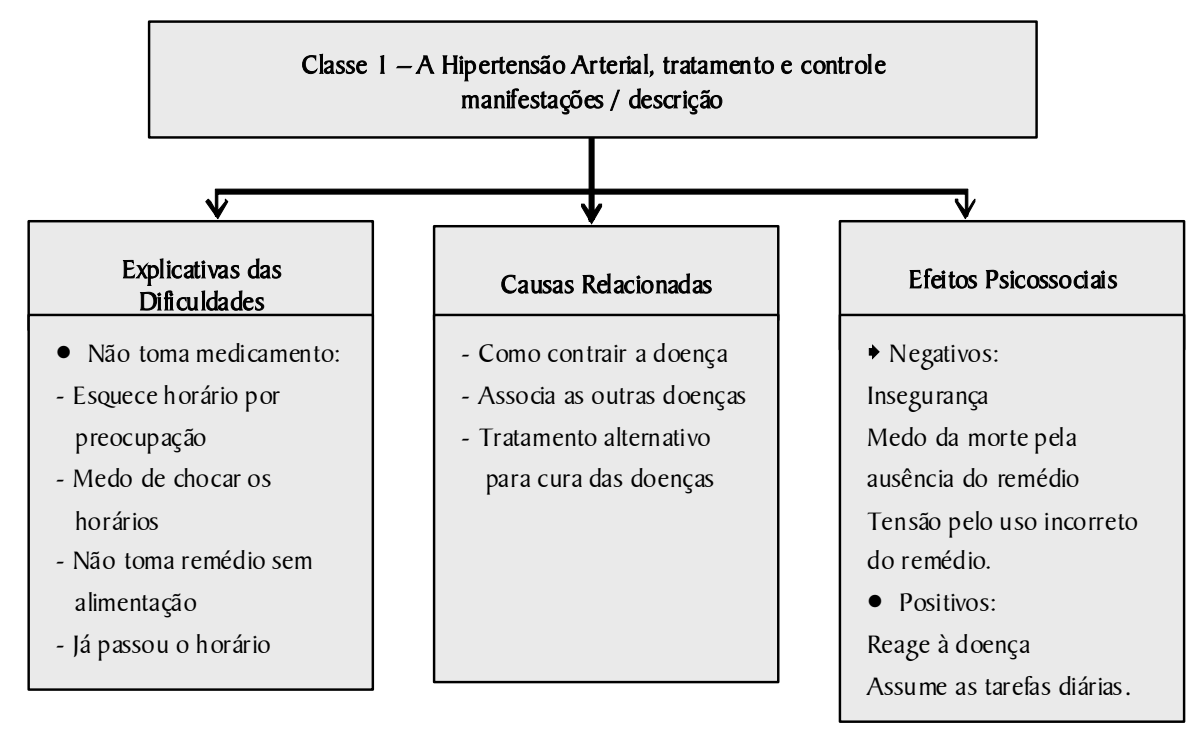

Figura 2. A Hipertensão Arterial, o tratamento e controle.

ser a HA uma doença perigosa requerendo uso sistemático e prolongado dos remédios prescritos pelo médico, acreditando nos seus efeitos miraculosos para a cura.

Os sujeitos, portadoras de HA, apresentam sentimentos ambíguos e contraditórios com relação à importância da medicação, pois ao tempo Que afirmam Que precisam tomar o remédio para toda a vida o esQuecem, resolvem diminuir as doses ou o abandonam, embora reconhecendo Que correm risco de morrer pelas complicações da doença:

(...) ela, em mim, eu acho que é uma doença muito perigosa. Eu tomo remédio todo dia, eu tomo dois comprimidos, um de manhã, outro de noite. (...) correndo risco de morrer QualQuer hora se esquecer do remédio (...). Ah! Para as outras pessoas, se elas não sofrem da doença elas acham Que, como é Que diz, pode chegar a elas e sofrerem a mesma coisa. (...) ele está apavorado de domingo para cá. A primeira coisa Que ele disse ontem à doutora foi Que nunca mais deixa de vir, nem de tomar o remédio.

As mulheres portadoras expressam sentimentos negativos Quanto à necessidade de adoção de novos hábitos relacionados ao uso da medicação, como, por exemplo, fazer refeições em horários não habituais como forma de garantir a tomada do remédio ou ainda, a obrigação de comparecer sistematicamente ao serviço de saúde, para buscar a medicação:

É! Eu não gosto de café, não tomo café, Quando eu tomo um cafezinho bem cedinho, às vezes, Quando vou tomar café com um pedaço de (...) só isso que eu tomo, aí eu já sei. (...), mas, meus remédios, antigamente eu não tomava. (...) não era acostumada, agora eu só tomo na hora, após o café. (...) eu não tomo Quando esqueço na hora, eu tenho medo de encontrar o horário, não é? (...) aí, eu chego no horário do café, porque no horário do café? Porque, mesmo que eu não tome café, eu levanto é cedo, (...) aí, eu fico com aquela impressão.

Portanto, esta classe mostra as dificuldades vivenciadas por essas portadoras, diante de um tratamento prolongado, para uma doença assintomática, fato Que pode contribuir para um resultado insatisfatório ou até mesmo o abandono definitivo do tratamento. Estudo semelhante numa comunidade carioca revela a experiência como única para cada portador e constitui barreiras Que mobilizam comportamentos, insatisfações e afetos e, muitas vezes, alteram a vida das pessoas, levando-as a resultados insatisfatórios na aceitação da doença em si e do tratamento com sua manutenção diária ${ }^{(15)}$.

A Classe 2 - Convivência Familiar - formada por 56 UCE (Figura 3) aponta as dificuldades das portadoras para o controle da Hipertensão Arterial, manifestada na convivência com seus familiares. Nessa, as palavras em suas formas reduzidas (Figura 1) se organizam em torno das Questões emocionais oriundas das relações conflituosas das portadoras com os familiares e da sobrecarga de afazeres domésticos Que se constituem fatores impeditivos do controle da doença.

O extrato dessas UCEs indica o conflito das portadoras na convivência com filhos e netos drogados, no cuidado das pessoas da família, em especial, dos netos menores, dos maridos doentes, Que demanda excesso de tarefas domiciliares Que acarretam estresses emocionais, dificultando o controle da doença:

(...) ela está até lá em casa agora (...), com vontade de ir embora. Estou pedindo a Deus que ela saia. (...) lá em casa eu moro só, meu marido morreu está com dois anos, duas filhas moram perto de mim, uma dum lado, outra no outro e eu bem no meio. (...) tem semanas que eu caminho três dias, tem semanas Que eu caminho Quatro, cinco. Agora, esse ano tem um menino, meu neto, Que o pai mora (..). Ele está comigo, mas, no final do ano ele vai para a casa dele. (...) eu faço café bem cedo. (...) a nora bem pertinho de mim, eu faço café para ela, para o marido 


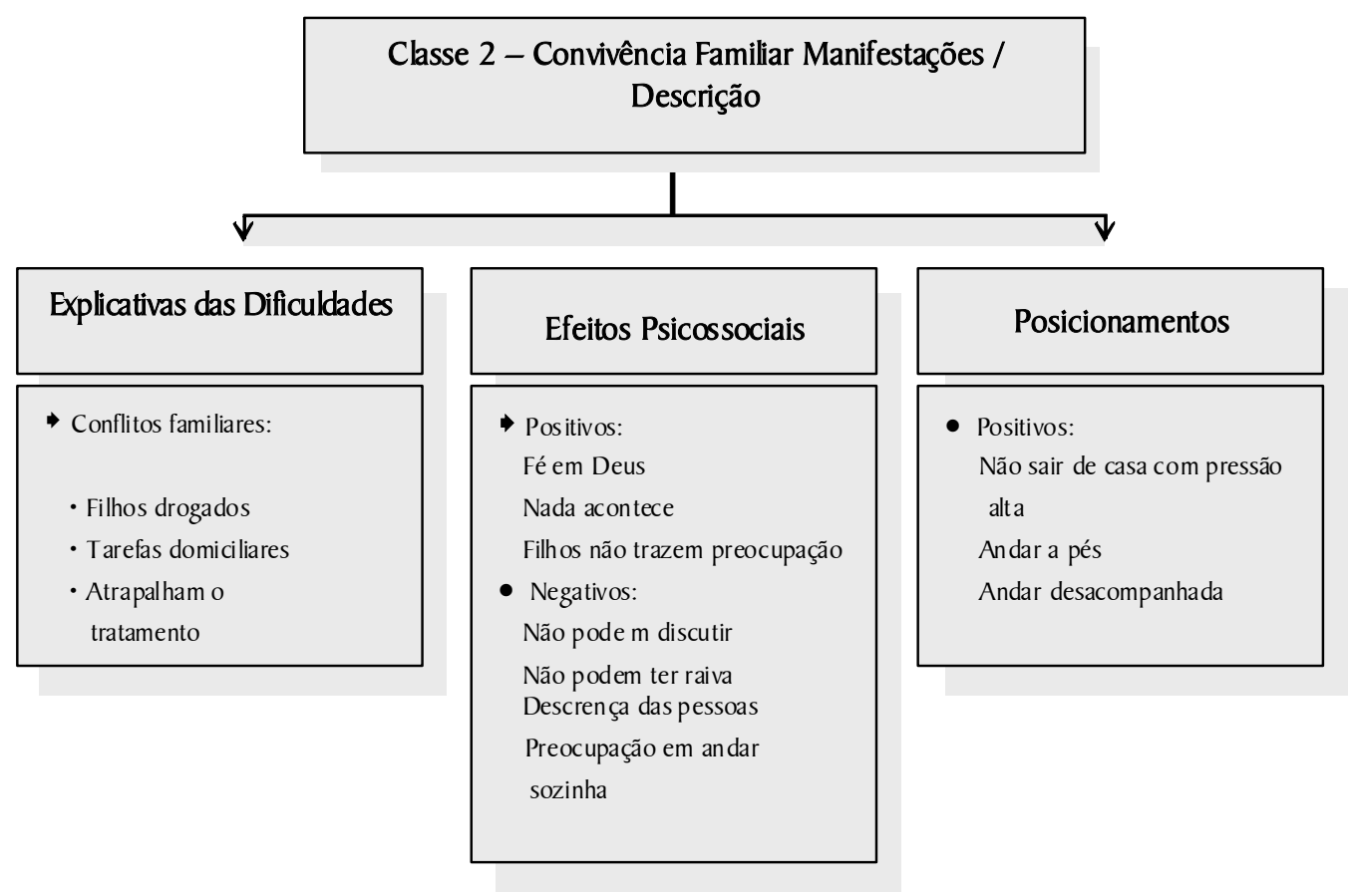

Figura 3. Convivência Familiar.

dela, o meninozinho e a filha. Aí, saio de Quitanda em Quitanda onde ele tem o costume de ir, para os Quitandeiros não venderem bebidas para ele. (...) ela teve AVC uma vez e em vez de cuidar de si, não, de jeito nenhum.

Apesar das barreiras encontradas, em geral, as mulheres hipertensas expressam a atenção especial dos filhos, filhas, maridos, vizinhos, entre outros, o Que faz essa convivência mais suportável:

(...) ela é Quem se preocupa mais. Todo dia ela vai lá em casa, porque é uma calçada só, Quase, não é? Aí, ela vai e pergunta: - como é Que está velha? Eu digo: - estou boa, estou melhor. (...) os meus filhos todos compreendem que eu tenho a doença. Às vezes, eles brigam, porQue eu gosto de sair. (...) os meninos brigam porque eu gosto de sair para a casa de uma filha Que mora (...).

Como forma de amenizar o desconforto de conviver com tal doença, as mulheres recorrem também a Deus por sua força suprema, considerando Que Deus impedirá que nada de mau lhes aconteça, principalmente, Quando saem de casa, sozinhas, em busca dos serviços de urgência, sentindo alterações Que atribuem serem decorrentes da pressão arterial elevada. O medo da morte súbita faz com Que dispensem a companhia dos filhos como forma de protegê-los do sofrimento caso cheguem a óbito em decorrência das complicações da pressão alta:

(...) enquanto eu puder andar eu vou só. Só não me preocupo muito porque a gente tem fé em Deus e nada acontece (...). Quando saio de casa já saio logo me apegando com Deus. (...) eu digo: Quando vierem saber já estou no buraco, enterrada. (...) só se for um caso necessário. (...) um dia o médico perguntou: - você tem filho? - não, é porQue meus filhos não me acompanham, eu não gosto. Vai Que não recupero, o Que é Que eu vou fazer? Não Quero, prefiro ir só. (...) eu digo: - Quando vierem saber já estou no buraco, enterrada.

As falas supracitadas apontam mais uma vez o conhecimento das mulheres portadoras, de Que a HA é uma doença relacionada às alterações emocionais da vida conturbada Que as submetem a muitos estresses. Desse modo, a adesão às práticas recomendadas como as atividades físicas, muitas vezes, é dificultada por não terem disponibilidade pela sobrecarga de trabalho, na ajuda à família.

O Subeixo 2 - formado pela Classe 3 - evidencia os sentimentos das portadoras acerca do processo de adoecer de HA. Nesse, a Classe 3 - Sentimentos das Portadoras - apresenta-se indiretamente relacionada às demais classes, composta por 107 unidades de contexto elementar (UCE) emergidas do discurso coletivo das portadoras dos grupos focais 4, 5, 6 e 7, sendo a classe de maior contribuição no Corpus, correspondendo a 22,8 $1 \%$ e Que evidencia os conteúdos psicossociais positivos, neutros e negativos, relativos aos sentimentos das mulheres como portadoras de HA.

As palavras, em suas formas reduzidas (Figura 1), selecionadas pela freqüência e pelos valores de médias 2 vezes mais elevadas, objetivam as Representações Sociais dessas portadoras, destacando os sentimentos Que denotam os efeitos psicológicos negativos explicitados pela insegurança, preconceito, frustrações e temores, sobretudo, das complicações Que causam a invalidez e morte, como acontece no Acidente Vascular Cerebral.

Os vocábulos (Figura 4) trazem a evidência de Que a HA, embora não comprometa as portadoras em relação às atividades diárias, produz limitações na vida social, considerando Que essas mulheres se sentem diferentes das demais e vivem sob constantes ameaças dos agravos, Que podem comprometê-las, destacando os fatores 


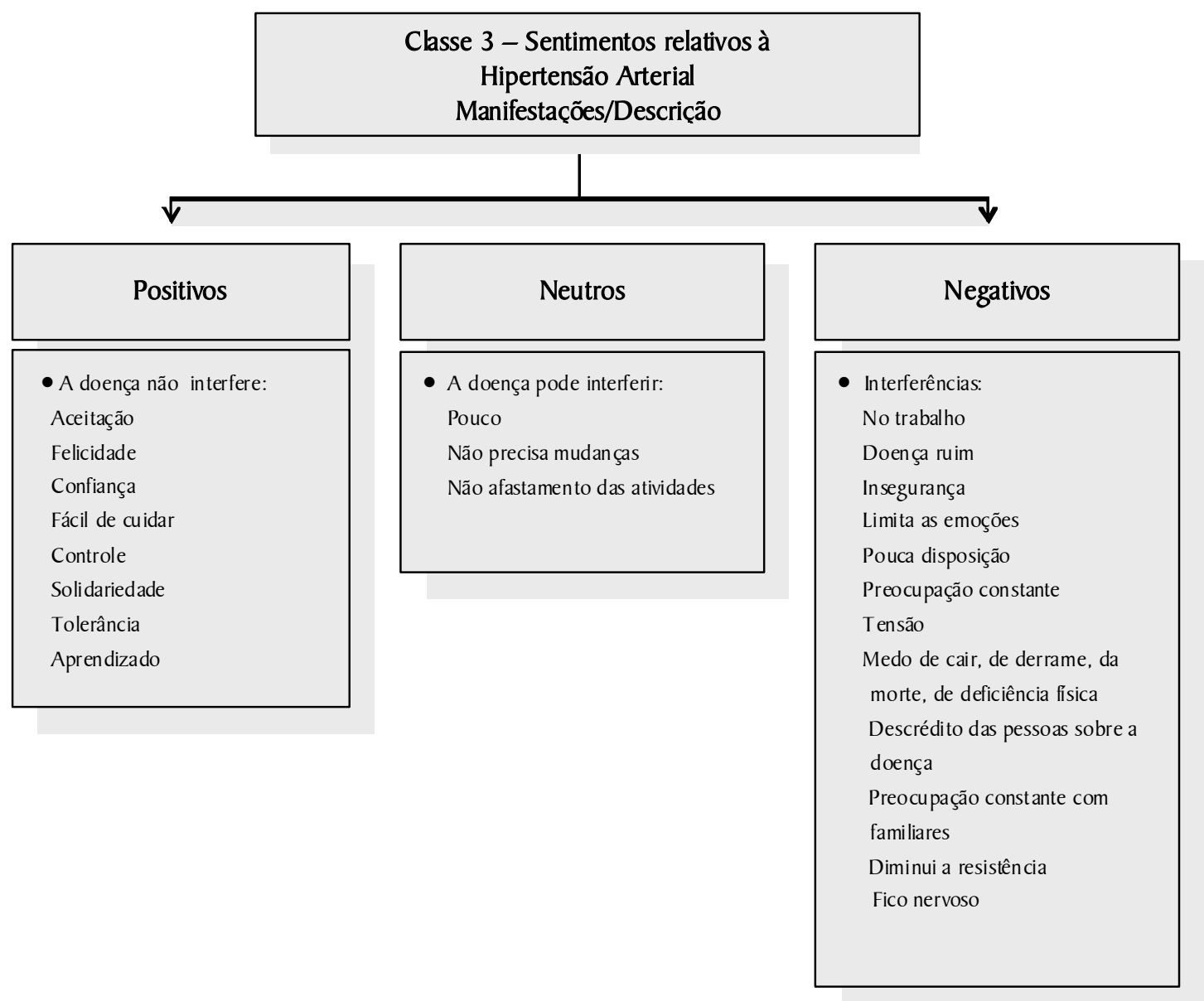

Figura 4. Sentimentos relativos à Hipertensão Arterial Manifestações/descrição.

emocionais Que podem agravar a doença:

(...) A gente já ficou muito abalada em não poder fazer o Que fazia, trabalhar a gente faz, mas, tem Que sentar um pouco porQue não dá, a gente fica cansada, tonta. (...) não tira da cabeça e aí, é o caso de ficar lá em baixo, ficar se sentindo doente, mesmo que a gente não sinta, a gente fica doente, porQue fica preocupada. (...) tudo acontecendo, minha irmã, o Que foi isso?

No discurso analisado fica claro a idéia de Que corpo e mente estão intrinsecamente relacionados podendo o estado mental/ emocional provocar alterações manifestas no corpo, no caso, elevar a pressão arterial.

Embora não haja comprovações de Que as alterações emocionais tenham participação direta nos fatores considerados psicossociais na produção do adoecer, essas indicam a possibilidade da existência de fatores estressores isolados para algumas doenças. Nesse sentido, pode-se inferir Que o "nervoso", as "emoções”, a "pressão alta" objetivam as representações sociais da HA.

Ao contrário, no conteúdo das UCEs seguintes, evidencia-se aspectos psicológicos positivos, demonstrados pela aceitação, tolerância, normalidade e confiança das portadoras por acreditarem Que a HA é uma doença Que pode ser controlada e possibilitar uma vida normal desde Que as portadoras dominem as fortes emoções e sigam as orientações para o tratamento da doença:

(...) Não, eu acho Que a pressão alta não interfere tanto, porQue graças a Deus eu hoje me sinto muito feliz pela pressão. Eu acho Que não interfere tanto e interfere porQue é doença mesmo. (...) porQue a gente se preocupa mais você e vai ficar mais doente ainda. (...) Eu digo assim, mesmo não estando com a pressão alta, não é, porQue a doença tem hora Que ela tem pressão alta, tem hora Que ela não tem. Eu aprendi muitas coisas, convivendo dentro de casa com meus filhos, porQue Quando eu sentia alguma coisa, Que a pressão alterava, eles diziam assim, mãe tente controlar a emoção, cuidado com a sua pressão.

Os aspectos psicológicos neutros foram ressaltados, ainda Que apareçam com menos freeüências e refiram-se à indiferença das portadoras em relação à convivência com a doença, não sentindo necessidade de alterar a rotina do trabalho:

(...) estavam sentindo tontura Que se sentiam impossibilitadas de fazer alguma coisa. Aí, assim (...), a interferência é maior, mas, se não, a interferência Que chega é pouca, elas continuam fazendo tudo, até que tenham alguma coisa forte, um impacto forte na pressão, senão, não mudam muito.

Os aspectos psicológicos positivos, negativos e neutros descritos neste subeixo revelam que as mulheres apresentam posicionamentos 
contraditórios e sentimentos ambíguos, os Quais podem contribuir para a dificuldade de controle da HA. Parte das portadoras manifesta medo em decorrência de algumas conseQüências da doença Quando não controlada, contribuindo para a adoção de comportamentos positivos em relação aos cuidados com a doença, embora, se identifique outro fator interveniente na decisão de adotar um comportamento favorável à saúde.

Estudos reforçam Que as representações sociais da doença remetem às raízes tradicionais da percepção de mundo dos indivíduos, com suas crenças e valores, sendo essas relativas à morte, à vida e às suas experiências vividas. É possível, portanto, Que este aspecto ocorra numa tentativa das mulheres negarem ou serem indiferentes à condição de portadoras de uma doença, como forma de se defenderem de alguns sentimentos como o medo e a ansiedade $^{(16,17)}$.

\section{CONCLUSÃO}

As classes apresentadas neste estudo evidenciam os conhecimentos elaborados e compartilhados socialmente, pelas portadoras da HA em seus grupos de pertença. Esses saberes circulam pela comunicação intra e intergrupal e suscitam comportamentos, sentimentos, posicionamentos e efeitos psicológicos relacionados ao processo de se adoecer e conviver com a doença.
Nesse sentido, a Teoria das Representações Sociais contribui para o entendimento psicossocial da doença, no âmbito da adoção de medidas preventivas pelas portadoras e profissionais de saúde. Com base nessa abordagem, o estudo traz o conhecimento a partir do Que vivenciaram ou vivenciam as mulheres em relação à doença, como facilitador da apreensão das representações presentes nas manifestações/descrições e explicações Que justificam os posicionamentos, destacando os efeitos psicossociais e orgânicofísicos, sentimentos expressos.

Em face deste estudo, certifica-se de Que as ações de educação em saúde realizadas pelos profissionais, em especial os de Enfermagem, não podem ser propostas sem Que se considere a diferença entre os grupos sociais e a interação com o saber prático pré-existente. Ressalta-se a partir das análises que a potencialidade da contribuição da Teoria das Representações Sociais como base da avaliação de programas de saúde pode contribuir com uma análise mais abrangente da complexidade das práticas sociais das portadoras em relação à HA.

O conhecimento das Representações Sociais da HA construído a partir de experiências subjetivas de portadoras em seu convívio familiar, de sua interação social e das barreiras vivenciadas frente ao tratamento pode contribuir significativamente para compreensão da relação desses portadores consigo mesmo e com o mundo em Que vivem.

\section{REFERÊNCIAS}

1. Mano R. Considerações gerais sobre hipertensão arterial sistêmica. [citado 10 jul 2003]. Disponível em URL: http:// www.manuaisdecardiologia.med.br.

2. Vieira FH. Reatividade pressórica em testes de estresse mental em indivíduos normotensos com hiper-atividade pressórica do teste ergométrico [dissertação]. Vitória (ES): Universidade Federal do Espírito Santo; 1993.

3. Horwitz RI, Horwitz SM. Adherence to the treatment and health outcomes. Arch Intern Med 1993; 153: 1863-68.

4. Barbosa MRJ. Vivenciando a hipertensão arterial: construção de significados e suas implicações para a vida cotidiana. Rev Bras Enferm 2000; 53(4): 574-83.

5. Ministério da Saúde (BR). Secretaria Nacional de Doenças Crônico-Degenerativas. Programa Nacional de Educação e Controle da Hipertensão Arterial. Normas Técnicas para o Programa Nacional da Hipertensão Arterial (PNECHA). Brasília (DF): Centro de Documentação do Ministério da Saúde; 1988.

6. Abric IC. Abordagem estrutural das representações sociais. In Moreira ASP, Oliveira DC, organizadores. Estudos interdisciplinares de representação social. Goiânia (GO): AB, 1998. p. 27-46.

7. Bursztyn I, Tura LFR. Avaliação em saúde e a Teoria das Representações Sociais: notas para análise de possíveis interfaces. In: Moreira ASP, Jesuino IC, organizadores. Representações Sociais: teoria e prática. João Pessoa (PB): Editora Universitária, 2003. p. 91-3.

8. Moscovici S. La Psychanalyse, son Image et son Public: étude sur la représentation sociale da psychanalise. Paris (FR): PUF; 1961.

9. Tura LFR. Aids e estudantes: a estrutura das representações sociais. In: Jodelet DE, Madeira M, organizadores. Aids e representações sociais: à busca de sentidos. Natal (RN): Editora UFRN, 1998. p. 121-54.

10. Moscovici S. A representação social da psicanálise. Rio de Janeiro (RJ): Zahar Editores; 1978.

11. Ministério da Saúde (BR). Conselho Nacional de Saúde. Comissão de ética e Pesquisa (CONEP). Resolução no. 196/ 1996, sobre pesQuisa envolvendo seres humanos. Brasília (Df): Ministério da Saúde; 2003.

12. Carlini-Cotrin B. Potencialidades da técnica Qualitativa grupo focal em investigações sobre abuso de substâncias. Rev Saúde Pública 1996; 30(3): 285-93.

13. Reinert M. Alceste. Analyse de donnes textuelles. Paris (FR): Societé IMAGE; 1998,

14. Nascimento-Schulze CM. As contribuições do enfoque psicosocial para o cuidado junto ao paciente portador de câncer. In: Dimensão da dor no câncer. São Paulo (SP): Robe editorial, 1997. p. 40.

15. Alves MGM. A voz do hipertenso: as representações socais da hipertensão arterial - estudo de caso em Jurujuba, Niterói [dissertação]. Rio de Janeiro (RI): Escola Nacional de Saúde Pública/ FIOCRUZ; 1998.

16. Alves PC, Minayo MCS, organizadores. Saúde e doença: um olhar antropológico. Rio de Janeiro (RJ): FIOCRUZ; 1994.

17. Péres DS, Magna JM, Viana LA. Portador de hipertensão arterial: atitudes, crenças, percepções, pensamentos e práticas. Rev de Saúde Pública 2003; 37(5): 635-42. 